\title{
Serum Neopterin Level in Early Onset Neonatal Sepsis
}

\author{
Fathia Sayed El Nemer ${ }^{1}$, Dina Abdel Razek Midan ${ }^{1}$, Ahmed Fouad Mohamed ${ }^{1,2, *}$ \\ ${ }^{1}$ Pediatric Department, Faculty of Medicine, Menoufyia University, Shebin al-Kom, Egypt \\ ${ }^{2}$ Zagazig medical center - Ministry of Health Sharkia, Egypt
}

Email address:

dr_a_fouad0202@yahoo.com (A. F. Mohamed)

\section{To cite this article:}

Fathia Sayed El Nemer, Dina Abdel Razek Midan, Ahmed Fouad Mohamed. Serum Neopterin Level in Early Onset Neonatal Sepsis. American Journal of BioScience. Vol. 3, No. 3, 2015, pp. 80-86. doi: 10.11648/j.ajbio.20150303.13

\begin{abstract}
Objective: The Aim of the study is to evaluate the diagnostic and prognostic values of serum neopterin level in neonatal sepsis and to evaluate risk factors for neonatal sepsis in neonatal intensive care unit of Menoufyia University hospital. Background: Neonatal sepsis has been used to describe the systemic response to infection in the newborn infant younger than one month age. Neopterin is one of biochemical markers of immune activity, which seems to be useful in monitoring inflammatory diseases. Increased concentration of neopterin in serum is observed in conditions with involvement of cellmediated immune response. Methods: Our study was conducted on 88 neonates recruited from NICU of and divided to Group I (suspected sepsis), It includes 35 neonates with symptoms and signs suggestive of sepsis or at high risk of infection. Group II (proven sepsis), It includes 38 neonates who are septic with clinical picture of sepsis and laboratory data showing sepsis, Group Ш (Controls), It includes 15 healthy neonates with no evidence of sepsis, all groups were subjected to history taking, clinical examination and laboratory Investigations included complete blood count, blood cultures, Quantitative Creactive protein (CRP) and Serum neopterin level. Results: Serum neopterin was significantly high in Group I (44.46 \pm 24.72$)$ and Group II (108.37 \pm 22.38$)$ than in controls and the best cutoff value of serum neopterin to detect sepsis is $70.56 \mathrm{nmol} / \mathrm{L}$ with sensitivity $94.7 \%$ and specificity $88.6 \%$.and that neopetrin correlated well with mortalities due to sepsis. Conclusion: Neopterin found to be a diagnostic and prognostic factor in patients with sepsis.
\end{abstract}

Keywords: Neopterin, C-Reactive Protein (Crp), Neonatal Sepsis

\section{Introduction}

Neonatal sepsis has been used to describe the systemic response to infection in the newborn infant younger than one month of age and is categorized as early or late neonatal sepsis(1).Each year, an estimated four million neonatal deaths occur globally. Infections account for about $36 \%$ of these deaths. Forty percent of these four million neonatal deaths occur in developing countries(2).

There are two clinical types of sepsis, Early onset sepsis (EOS) presents within the first 72 hours of life. In severe cases, the neonate may be symptomatic at birth. Infants with EOS usually present with respiratory distress and pneumonia. Late onset sepsis (LOS) usually presents after 72 hours of age. The source of infection in LOS is either nosocomial (hospital-acquired) or community-acquired and neonates usually present with septicemia, pneumonia or meningitis (3).

Warning signs and symptoms are often subtle and can easily be confused with non infective causes such as apnea, hypothermia, and acute exacerbation of chronic lung disease. So that haematological and biochemical markers such as immature/total neutrophil ratio, platelet count, Creactive protein (CRP), various cytokines have been proposed as being useful indicators for early identification of septic infant(4).

The unnecessary exposure to antibiotics, with emergence of bacterial resistance will lead to potential poor outcomes in this vulnerable population of neonates. To identify accurately neonates with sepsis, attempts have been made to use physiologic parameters, hematologic indices, and cytokine profiles, at the time of onset of the suspected sepsis episode (5). Despite extensive investigation, no single test meets the criteria that would make it an ideal marker for early diagnosis of sepsis in the newborn. Generally screening includes a complete blood count with differential and may be accompanied by other adjuvant tests such as a C-reactive protein (CRP) (6).

Neopterin a pyrazino - pyrmidine derivative is formed from guanosione triphosphate within the biosynthetic 
pathway of biopterin. It is produced by the human macrophages when stimulated by interferon gama released from activated $\mathrm{T}$ lymphocyte( 7 ). Neopterin is one of biochemical markers of immune activity, which seems to be useful in monitoring inflammatory diseases. Increased concentration of neopterin in serum is observed in conditions with involvement of cell mediated immune response (8).

\section{Patients and Methods}

The studied newborns were divided into three groups, Group I (suspected sepsis) included 35 neonates with symptoms and signs suggestive of sepsis or at high risk of infection, Group II (proven sepsis) included 38 neonates who are septic with clinical picture of sepsis and laboratory data showing sepsis, Group Ш (Controls) included 15 healthy neonates with no evidence of sepsis .Exclusion criteria were Severe congenital anomalies ,Chromosomal abnormalities, Intra- uterine growth retardation, preterms, Perinatal asphyxia and Infant of diabetic mother.

All groups were subjected to history taking (to detect risk factors for sepsis) including obstetric, prenatal, natal, postnatal and present history ; Full clinical examination including general examination ,cardio vascular examination ,chest examination, neurological examination, abdominal examination and Skin examination .

Laboratory Investigations included complete blood count (CBC) with differential count, Blood cultures using neonatal bottles and sub cultured on blood agar plate, Antibiotic sensitivity test was done by Kirby Baur Technique, Quantitative C-reactive protein (CRP) using Latex agglutination test, Rapitex CRP kit. It was considered positive when the titer was $>6 \mathrm{mg} / \mathrm{L}$ and Serum neopterin level done at the time of diagnosis of the case and will be measured by an enzyme linked immunosorbent assay (ELISA) technique using kit purchased from IBL international GMBH Hamburg Germany. Two $\mathrm{ml}$ of blood were withdrawn from a peripheral vein after taking an informed consent from parents of patients and controls. The sera were separated by centrifugation at $3500 \mathrm{rpm}$ for 10 minutes. Sera were stored at $-20 \mathrm{C}$ till the time of assay.

\section{The Statistical Analysis}

Descriptive statistics: e.g. percentage (\%) as clinical sepsis score, results of blood culture, occurrence and distribution of complications and survival of the studied groups. Mean X and standard deviation (SD) as for gestational age, weight, length, head circumference, gender and vital signs. Analytic statistics: e.g. Chi-square (X2) test, standard t-test and Fisher Exact test. Chi-square (X2) test: was used for comparison between qualitative variables in different groups, e.g. comparison of manifestations of sepsis in studied neonates. Studied t-test: was used for comparison between quantitative variables in different groups (e.g., age, sex, weight, length, head circumference and Apgar score).Fisher Exact test: for comparison between quantitative data whenever appropriate. The accepted level of significance in this work was stated at 0.05 ( $\mathrm{P}<0.05$ was considered significant. ROC curve was used to compare neoptrein and CRP in diagnosing neonatal sepsis and prediction of its outcome.

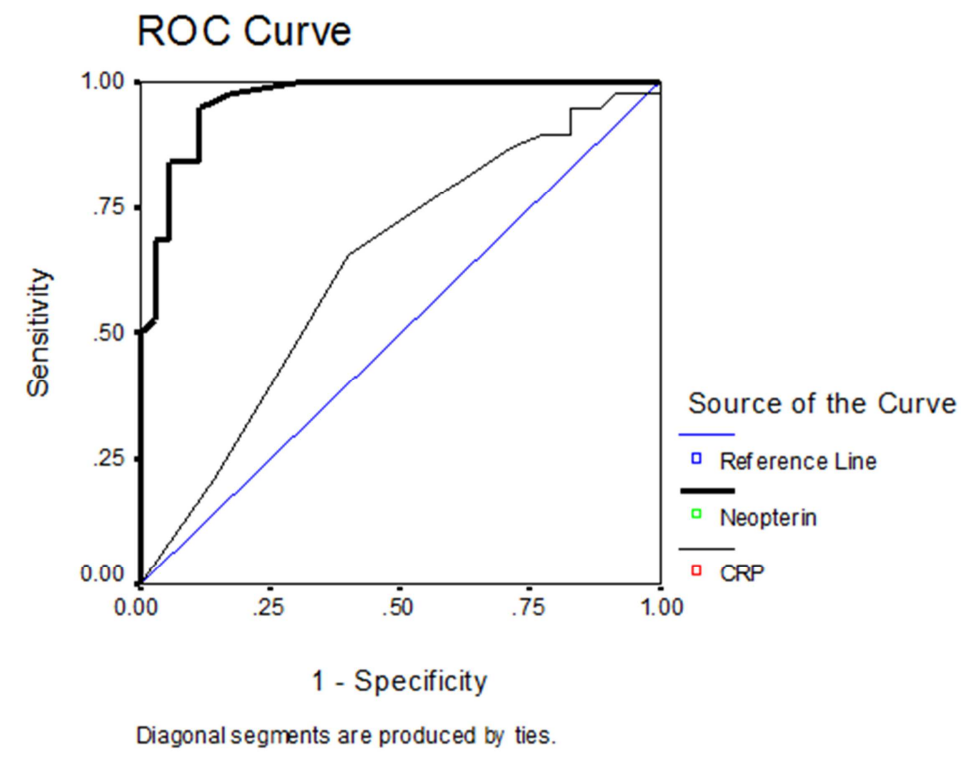

Figure 1. Receiver operating characteristic curve (ROC) for evaluation of neopterin \& CRP in diagnosis of sepsis.

\section{Results}

The demographic data shown significant differences between demographic parameters. There were high significant differences between the studied groups as regard APGAR (1 min) and APGAR (5 min)as shown in table (2). There was significant difference between Group I and Group II regarding clinical sepsis score being higher in Group II as shown in table (3). Ragarding CBC results shown in table (4) 
there were high significant differences between the case groups as regard Platelets, Immature neutrophil and immature to mature neutrophil $(\mathrm{I} / \mathrm{M})$ ratio and Hematological sepsis score . while non-significant differences between the case groups were found as regard haemoglobin, Total Leucocytic Count ,Total neutrophil and immature /total neutrophil ratio .Pseudomonas shows the highest percent of incidence being $(17.1 \%)$ in blood cultures of Group I followed by Klebseilla (11.4\%),E. coli (11.4\%) ,Staph aureus(11.4\%), and lastly Enterobacter (5.7\%). In Group II, Klebseilla shows the highest percent of incidence being (36.8\%) followed by Staph aureus $(28.3 \%)$ followed by E. coli (18.4\%) followed by Pseudomonas (15.8\%), and lastly Staph. Epidermidis (2.6\%) The organisms in Group I were sensitive to Meropenem (35\%) then Amikacin (15\%), Ciftazidim (15\%), Ceftriaxon (10\%) and Ciprofloxacin $(10 \%)$ then Cefepim (5\%), Gentamycin (5\%) and Vancomycin (5\%). Also the organisms in Group Group II were sensitive to Meropenem (34.2\%) then Amikacin $(18.4 \%)$ then Vancomycin (15.8\%) then Ciprofloxacin $(10.5 \%)$ then Ceftriaxon (7.9\%) and Gentamycin $(7.9 \%)$ then Ciftazidim (5.3\%). as shown in table (5). There were significant difference between the studied groups as regard CRP and ESR shown in table (6). There were high significant difference between the studied groups regarding neopterin level being higher in Group II(108.37 \pm 22.38$)$ than Group I (44.46 \pm 24.72$)$ and Group III $(5.35 \pm 2.34)$ as shown in table (7).The level of Neopetrin was high in died cases compared to Survived this shows the value of neopetrin evaluating in prognosis of the septic neonates cases as shown in table (8).Our study revealed that the best cutoff value of serum neopterin to detect sepsis is $70.56 \mathrm{nmol} / \mathrm{L}$ with sensitivity $94.7 \%$ and specificity $88.6 \%$ while CRP with cut off level 36 , sensitivity $65.8 \%$ and Specificity $60.0 \%$ as shown in table (9).

Table (1). Demographic data of the studied groups.

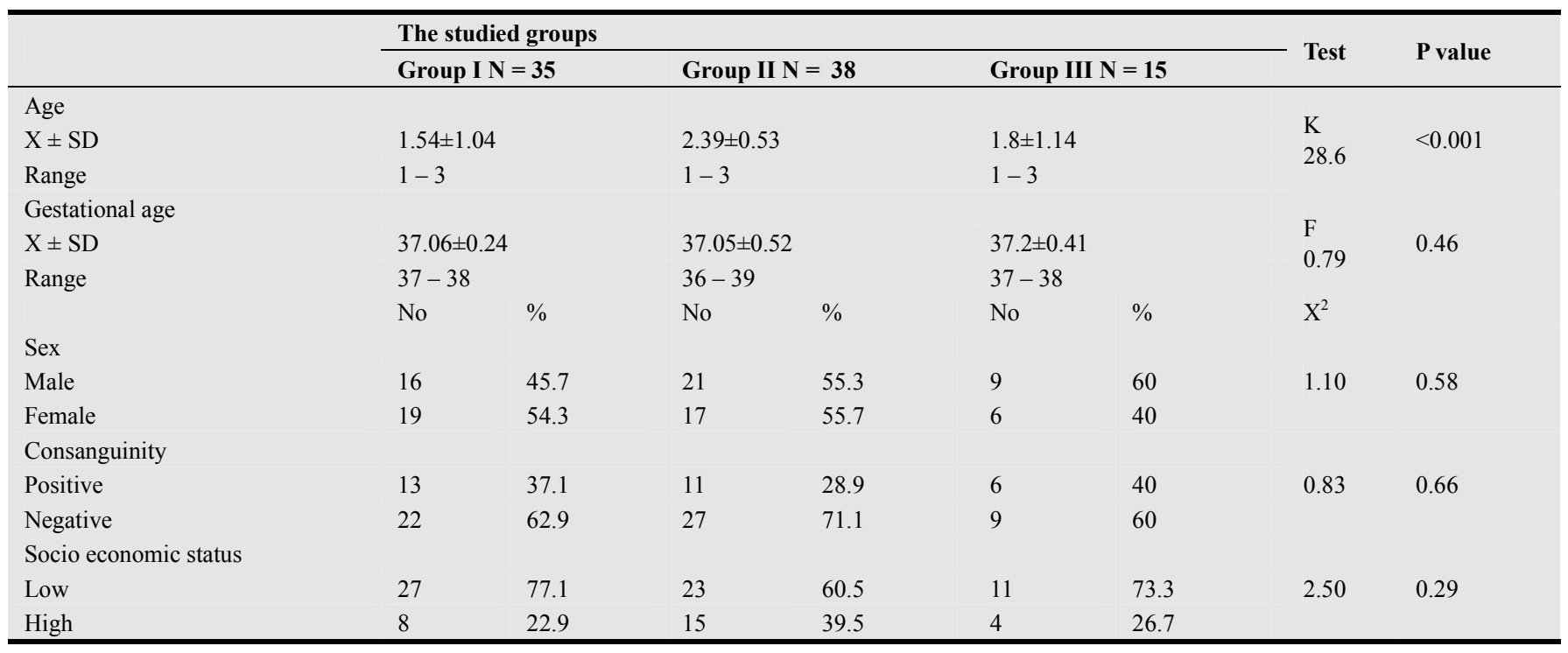

GroupI $=$ Suspected sepsis Group II = proven sepsis Group III = control

Table (2). Clinical data of the studied groups.

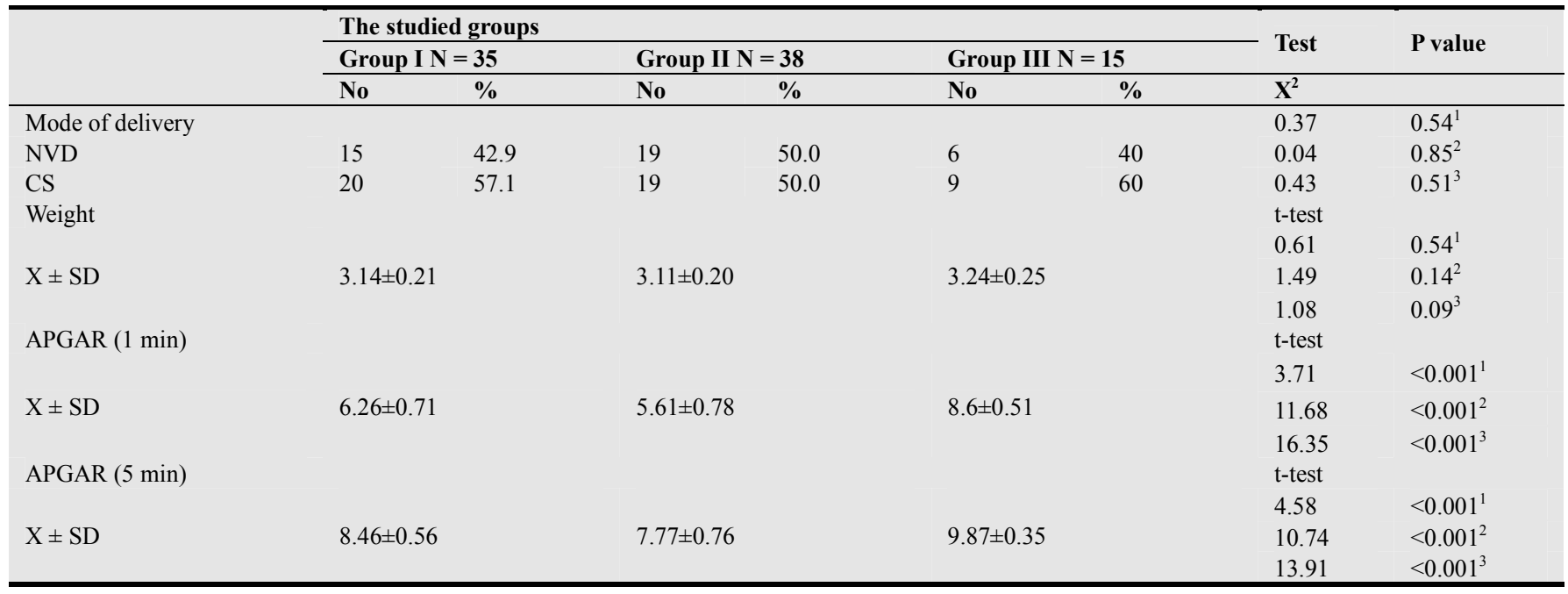


Table (3). Clinical sepsis score among the studied cases.

\begin{tabular}{|c|c|c|c|c|}
\hline & \multicolumn{2}{|c|}{ The studied groups } & \multirow{2}{*}{ t- test } & \multirow{2}{*}{ P value } \\
\hline & Group I N $=35$ & Group II N = 38 & & \\
\hline \multicolumn{5}{|l|}{ Clinical sepsis score } \\
\hline $\mathrm{X} \pm \mathrm{SD}$ & $4.29 \pm 1.18$ & $5.05 \pm 1.64$ & 2.31 & 0.02 \\
\hline Range & $3-7$ & $4-8$ & & \\
\hline
\end{tabular}

Table (4). Complete blood count results of the studied groups.

\begin{tabular}{|c|c|c|c|c|}
\hline & \multicolumn{2}{|c|}{ The studied groups } & \multirow{2}{*}{ Test } & \multirow{2}{*}{ P value } \\
\hline & Group I N = 35 & Group II N = 38 & & \\
\hline $\mathrm{Hb}(\mathrm{g} / \mathrm{dl})$ & & & t-test & \\
\hline TLC (cell/mm3) & & & $\mathrm{U}$ & \\
\hline $\mathrm{X} \pm \mathrm{SD}$ & $20.55 \pm 7.37$ & $21.79 \pm 6.08$ & 0.97 & 0.33 \\
\hline Platelets (cell/mm3) & & & $\mathrm{U}$ & \\
\hline $\mathrm{X} \pm \mathrm{SD}$ & $156.6 \pm 71.38$ & $91.39 \pm 49.64$ & 3.95 & $<0.001$ \\
\hline $\operatorname{RBCs}\left(\times 10^{6}\right)$ & & & t-test & \\
\hline $\mathrm{X} \pm \mathrm{SD}$ & $4.14 \pm 0.38$ & $3.93 \pm 0.31$ & 2.58 & 0.01 \\
\hline Total neutrophil (cell/mm3) & & & U & \\
\hline $\mathrm{X} \pm \mathrm{SD}$ & $10.85 \pm 5.26$ & $12.31 \pm 4.54$ & 1.18 & 0.24 \\
\hline Immature neutrophil(cell/mm3) & & & $\mathrm{U}$ & \\
\hline $\mathrm{X} \pm \mathrm{SD}$ & $3.06 \pm 1.11$ & $3.66 \pm 0.88$ & 2.13 & 0.03 \\
\hline $\mathrm{X} \pm \mathrm{SD}$ & $0.25 \pm 0.09$ & $0.27 \pm 0.07$ & 0.59 & 0.55 \\
\hline $\mathrm{I} / \mathrm{M}$ ratio & & & $\mathrm{U}$ & \\
\hline $\mathrm{X} \pm \mathrm{SD}$ & $0.37 \pm 0.13$ & $0.49 \pm 0.13$ & 3.53 & $<0.001$ \\
\hline Hematological sepsis score & & & t-test & \\
\hline HSS & & & 4.15 & $<0.001$ \\
\hline $\mathrm{X} \pm \mathrm{SD}$ & $4.34 \pm 1.08$ & $5.53 \pm 1.33$ & & \\
\hline
\end{tabular}

Table (5). Organisms revealed fom blood cultures and antibiotic sensitivity of the studied cases.

\begin{tabular}{|c|c|c|c|c|c|c|}
\hline & \multicolumn{4}{|c|}{ Blood culture positive cases } & \multirow{3}{*}{$\begin{array}{l}\text { Test } \\
\mathbf{X}^{2}\end{array}$} & \multirow{3}{*}{ Pvalue } \\
\hline & \multicolumn{2}{|c|}{ Group I N = 35} & \multicolumn{2}{|c|}{ Group II N = 38} & & \\
\hline & No & $\%$ & No & $\%$ & & \\
\hline \multicolumn{7}{|l|}{ Organisms } \\
\hline No growth & 15 & 42.9 & 0 & 0 & \multirow{7}{*}{26.9} & \multirow{7}{*}{$<0.001$} \\
\hline Staph aureus & 4 & 11.4 & 10 & 28.3 & & \\
\hline Staph. Epidermidis & 0 & 0 & 1 & 2.6 & & \\
\hline E. coli & 4 & 11.4 & 7 & 18.4 & & \\
\hline Enterobacter & 2 & 5.7 & 0 & 0 & & \\
\hline Pseudomonas & 6 & 17.1 & 6 & 15.8 & & \\
\hline Klebseilla & 4 & 11.4 & 14 & 36.8 & & \\
\hline Gram stain & $\mathrm{N}=20$ & & $\mathrm{~N}=38$ & & \multirow{3}{*}{0.55} & \multirow{3}{*}{0.46} \\
\hline Gram positive & 4 & 20 & 11 & 28.9 & & \\
\hline Gram negative & 16 & 80 & 27 & 71.1 & & \\
\hline Antibiotic sensitivity & \multicolumn{2}{|l|}{$\mathrm{N}=20$} & \multicolumn{2}{|l|}{$\mathrm{N}=38$} & \multirow{9}{*}{4.93} & \multirow{9}{*}{0.67} \\
\hline Meropenem & 7 & 35 & 13 & 34.2 & & \\
\hline Amikacin & 3 & 15 & 7 & 18.4 & & \\
\hline Ceftriaxon & 2 & 10 & 3 & 7.9 & & \\
\hline Ciftazidim & 3 & 15 & 2 & 5.3 & & \\
\hline Cefepim & 1 & 5 & 0 & 0 & & \\
\hline Gentamycin & 1 & 5 & 3 & 7.9 & & \\
\hline Ciprofloxacin & 2 & 10 & 4 & 10.5 & & \\
\hline Vancomycin & 1 & 5 & 6 & 15.8 & & \\
\hline
\end{tabular}


Table (6). Acute phase reactants of the studied groups.

\begin{tabular}{lllll}
\hline & \multicolumn{1}{l}{ The studied groups } & \multirow{2}{*}{ Test of sig. } & P value \\
\cline { 2 - 4 } & Group $\mathbf{~} \mathbf{N}=\mathbf{3 5}$ & Group $\mathbf{I I} \mathbf{~}=\mathbf{3 8}$ & \\
\hline $\begin{array}{l}\mathrm{ESR} \\
\mathrm{X} \pm \mathrm{SD} \\
\mathrm{CRP}\end{array}$ & $31.0 \pm 6.12$ & $38.03 \pm 4.51$ & $5.62 \#$ & $<0.001$ \\
$\mathrm{X} \pm \mathrm{SD}$ & $34.98 \pm 30.05$ & $47.33 \pm 29.66$ & $2.03 \&$ & 0.04 \\
\hline
\end{tabular}

Table(7). Neopterin level of the studied groups.

\begin{tabular}{|c|c|c|c|c|c|}
\hline & \multicolumn{3}{|c|}{ The studied groups } & \multirow{2}{*}{ Kruskal Wallis test } & \multirow{2}{*}{$P$ value } \\
\hline & Group I N = 35 & Group II N $=38$ & Group III N = 15 & & \\
\hline \multicolumn{6}{|c|}{ Neopterin } \\
\hline \multirow[b]{2}{*}{$\mathrm{X} \pm \mathrm{SD}$} & $44.46 \pm 24.72$ & $108.37 \pm 22.38$ & $5.35 \pm 2.34$ & 6.82 & $<0.001^{1}$ \\
\hline & $11-111$ & $60-142$ & $1.3-9$ & $\begin{array}{l}5.56 \\
5.63\end{array}$ & $\begin{array}{l}<0.001^{2} \\
<0.001^{3}\end{array}$ \\
\hline
\end{tabular}

1. comparing group I and group II

2. comparing group I and group III

3. comparing group II and group III

Table(8). Neopetrin level in relation to outcome among the studied cases.

\begin{tabular}{|c|c|c|c|c|}
\hline & \multicolumn{2}{|c|}{ Outcome among cases } & \multirow{2}{*}{ Mann Whitney U } & \multirow{2}{*}{ Pvalue } \\
\hline & Survived N $=\mathbf{5 7}$ & $\operatorname{Died} N=16$ & & \\
\hline \multicolumn{5}{|c|}{ Neopetrin } \\
\hline $\mathrm{X} \pm \mathrm{SD}$ & $68.75 \pm 36.46$ & $109.69 \pm 34.97$ & 3.79 & $<0.001$ \\
\hline Range & $11-142$ & $35-142$ & & \\
\hline
\end{tabular}

ROC curve of CRP and neopterin to differentiate proved sepsis from suspected sepsis

Table (9). Sensitivity and Specificity of neopterin and CRP level as a markers in neonatal sepsis.

\begin{tabular}{lll}
\hline Parameters & CRP & Neopterin \\
\hline AUC & 0.63 & 0.96 \\
P value & 0.05 & $<0.001$ \\
Cutoff point & 36 & 70.5 \\
Sensitivity & 65.8 & 94.7 \\
Specificity & 60.0 & 88.6 \\
\hline
\end{tabular}

\section{Discussion}

Neonatal sepsis is defined as a clinical syndrome of bacteremia with signs and symptoms of infection in the first four weeks of life. When pathogenic bacteria gain access into the blood stream, they may cause overwhelming infection without much localization termed as septicemia or may get predominantly localized to the lungs resulting in pneumonia, or the meninges causing meningitis (9).A better understanding of the neonatal inflammatory response to sepsis and identification of sensitive and specific markers of inflammation or rapid microbe-specific diagnostic tests would assist in the early detection of neonatal sepsis (10).Elevated levels of neopterin have been shown to be early spesfic and sensitive marker responsible for activation of the cellular immune system in several clinical settings including allograft regection, acute bacterial infections, inflammatory and malignant diseases (11).
In our study we found that there were high significant differences between the studied groups regarding APGAR (1 min) and APGAR (5 min). Mean of Apgar score at 1 min was $6.26 \pm 0.71$ in Group I and5.61 \pm 0.78 in Group II while was $8.6 \pm 0.51$ in Group $\amalg$ with $p$ value $<0.001$. Mean value of Apgar score at 5 min was $8.46 \pm 0.56$ in Group I and $7.77 \pm 0.76$ in Group II while was $9.87 \pm 0.35$ in Group Ш with $p$ value $<0.001$. This agrees with the study of Yousef et al.,(12)who observed that, a 5-minute Apgar score $<7$ carries a significantly higher risk of sepsis than infants with higher scores and that Apgar score less than 5 at one minute may be due to sepsis, especially with the presence of risk factors for infection. Furthermore, low Apgar scores usually necessitate more prolonged and aggressive resuscitation which is a known risk factor for sepsis (13).

In the current study, it was found that positive blood cultures were $(100 \%)$ in the confirmed sepsis group and was $(58.8 \%)$ in the suspected sepsis group. Pseudomonas shows the highest percent of incidence being $(17.1 \%)$ in blood 
cultures of Group I followed by Klebseilla (11.4\%), E. coli (11.4\%), Staph aureus(11.4\%), and lastly Enterobacter (5.7\%). In Group II, Klebseilla shows the highest percent of incidence being (36.8\%) followed by Staph aureus $(28.3 \%)$ followed by E. coli (18.4\%) followed by Pseudomonas $(15.8 \%)$, and lastly Staph. Epidermidis (2.6\%).Also it was found that Staph aureus highly sensitive for Vancomycin(42.9\%),Staph. Epidermidis highly sensitive for Vancomycin (100\%), E. coli highly sensitive for Amikacin (36.4\%), Enterobacter highly sensitive for Amikacin ( 50\%), Pseudomonas highly sensitive for Amikacin (33.3\%) and Klebseilla highly sensitive for Meropenem (66.7\%).These findings are in agreementwith Abdel-Hady and Zakiet al., (14).reported that, klebsilla was found in $41.3 \%$ of patients. Also Badrawi et al., (15) reported that klebsiella $63.6 \%$. Boseila et al., (16) found that Klebseilla dominated the organisms isolated from the blood culture (35\%), followed by Pseudomonas (20\%), Coagulase Negative Staphylococci (10\%), Group B Streptococci (10\%), Staph. Aureus (10\%) and Enterobacter (15\%).

Also our study showed that there was leucocytosisin the septic and suspected neonates. This is in harmony with Mah et al.,(17) who studied the incidence of sepsis in100 neonates and found that $(90 \%)$ of them showed leucocytosis in their complete blood count before starting treatment .HSS was significantly higher in septic neonates either proved or suspected and the mean value of HSS in group II was $5.53 \pm 1.33$ and mean value in group I was $4.34 \pm 1.08$. This agrees with Yousef et al.,(12) and Fergany et al., (18) who reported that HSS was significantly higher in patients with infection than patients with no infection and that HSS of the septic group was $\geq 3$. El-Raggal et al.,(19) found that $93 \%$ of septic group had HSS $\geq 3$. Badrawi et al., (15) reported that HSS score $\geq 3$ should detect septic infants with a sensitivity of $98 \%$. They also suggested that HSS score $\geq 5$ are highly predictive of sepsis until a reliable diagnostic test is available.

In the current study, There was significant difference between the studied groups as regard CRP .The values of CRP were $34.98 \pm 30.05$ in Group I and 47.33 \pm 29.66 in Group II .Similar results were obtained in the study of Carrigan et al. ,20) who reported that concentrations of CRP in septic patients ranged from 12 to $159 \mathrm{mg} / \mathrm{dl}$. As the concentration of CRP increased rather slowly, in the initial phase, the sensitivity of sepsis evaluation was only $60 \%$. Serial measurements at 24 and 48 hours after the onset of illness considerably improved the sensitivity (21).

In the current study we found that serum neopterin was significantly high in Group I $(44.46 \pm 24.72)$ and Group II $(108.37 \pm 22.38)(\mathrm{P}<0.001)$ indicating that the serum neopterin level is a good marker for the diagnosis of neonatal sepsis. The same results was observed in the study done by Boseila et al., (16) who revealed that serum neopterin was significantly increased in the infected and suspected groups than the control group. Mitakaet al., (22) observed that neopterin level have been increased in patients progressing from gram negative sepsis to septic shock and it was reported that neopterin level are higher in patient with septic shock than in patients with non infectious SIRS and explained that neopterin biosynthesis in inflammatory state might be caused by increased levels of endogenous interferon gamma which was directly related to the extent of systemic T-lymphocyte activation. This finding can be easily explained because neopterin closely reflects the activation of both monocytes macrophages and endothelial cells, which have a central role in the pathogenesis of septic shock. This comes in agreement with Tasdelenet al., (23) who observed that neopterin is a coparameter in the diagnosis of bacterial infection as elevated concentration of neopterin are found to be relevant to the endothelial damage and septic complication, so neopterin is found to be a prognostic factor in patients with sepsis.Baydar et al., (24) Observed that serum neopterin level were significantly higher in all patients than in the control and explained that by neopterin is a biomarker of cellular immunity and therefore increased level of neopterin may reflect septic complications.

In the current study we found a positive correlation between serum neopterin level and the mortality rate in patients with sepsis as we found significant increase in serum neopterin in non survived (109.69 \pm 34.97$)$ nmol/lthan survived patients $(68.75 \pm 36.46) \mathrm{nmol} / \mathrm{l}$. This comes in agreement with Tasdelen et al., (23) who found a significant correlation between serum neopterin level and the mortality rate in patients with sepsis who explained that neopterin may contribute to tissue damage caused by increased cellular apoptosis. This also comes in agreement with Ruokonen et al., (25)who observed that increased neopterin level in non survivedare not soley related to the activity of the inflammatory response but also to the severity of the illness.

The combination of serum neopterin level and CRP is a reliable test for the diagnosis of early onset bacterial infection and may be helpful in establishing antibiotic therapy in newborn( 26 ). Boseila et al., (16) found that the combination of serum neopterin level and CRP is a reliable test for the diagnosis of early onset bacterial infection and may be helpful in establishing antibiotic therapy in newborn. For evaluation of value of neopterin in diagnosis of sepsis and comparing it with CPR we found that neopterin had a better sensitivity value $(94.7 \%)$ more better than CRP which had sensitivity value $(65.8 \%)$. The specificity of neopterin was $(88.6 \%)$ which was higher than that of CRP (60\%). Our study revealed that the best cutoff value of serum neopterin to detect sepsis is $70.56 \mathrm{nmol} / \mathrm{L}$ with sensitivity $94.7 \%$ and specificity $88.6 \%$.

\section{Conclusion}

Serum neopterin level increases significantly in neonates with confirmed sepsis and in neonates with suspection of sepsis. Neopterin found to be a diagnostic and prognostic factor in patients with sepsis. Neopterin may be a useful tool in prediction of mortality in neonatal sepsis. Combined use of one or more laboratory marker as HSS and CRP with neopterin will enhance the diagnostic accuracy, early 
detection and consequently prevention of complications of infected cases.

\section{Acknowledgments}

many thanks to Dr. Fathia Sayed El Nemer, assistant professor of pediatrics- Menoufyia University for putting the key-stone for this study, choosing such a useful topic and for her continuous generous supervision .I'm also deeply thankful to Dr. Dina Abdel Razek Midan, lecturer of pediatrics-Menoufyia University, for her great help, sincere cooperation, Patience, meticulous supervision and guiding instructions in preparing this work. Many thanks to my family (my parents, my brother, my sisterand my wife ). Deep thanks and gratitude for all members working in NICU of Menoufyia hospital for their cooperation. And many thanks to my neonates.

\section{References}

[1] Chacko B, Sohi I. Early onset neonatal sepsis.Indian J Pediatr.2005 Jan;72(1):23-6.

[2] Lawn JE, Cousens S, Zupan J; Lancet Neonatal Survival Steering Team. 4 million neonatal deaths: when? Where? Why? Lancet. 2005 Mar 5-11;365 (9462):891-900.

[3] Shankar M J, Agarwal R and Deorariak et al. sepsis in the newborn. AIIMS-NICU Protocols. 2008 :1-18.

[4] Ucar B, Yildiz B, Aksit MA, Yarar C, Colak O, Akbay Y, Colak E. Serum amyloid A, procalcitonin, tumor necrosis factor-alpha, and interleukin-1beta levels in neonatal lateonset sepsis. Mediators Inflamm. 2008; 2008:737141.

[5] Vineet Bhandari, Chao Wang, Christine Rinder and Henry Rinder. Hematologic Profile of Sepsis in Neonates: Neutrophil CD64 as a Diagnostic Marker. Pediatrics 2008;121;129-134.

[6] Hawak.C-reactive protien in neonatal sepsis, the journal of neonatal nursing, neonatal network 2008;(23)2:117-120.

[7] Cesur S. Neopterin: a marker used for monitoring infections. Mikrobiyol Bul.2005 Apr;39(2):251-60.

[8] Ip M, Rainer TH, Lee N, et al. Value of serum procalcitonin; neopterin; and C-reactive protein in differentiating bacterial from viral etiologies in patients presenting with lower respiratory tract infections. Diagn Microbiol Infect Dis 2007;59: 131-6.

[9] Khinchi Y R, Kumar A, Yadav S .Profile of Neonatal sepsis. Journal of college of Medical Sciences-Nepal, 2010 ;6(2): 1-6.

[10] Arnon S, LitmanovitzI .Diagnostic tests in neonatal sepsis. Curr Opin Infect Dis,2008;21(3):223-227.

[11] Takala A, Nupponen I, Kylänpää-Bäck ML, et al. .Markers of inflammation in sepsis. Ann Med,2002; 34(7-8):614-23.
[12] Yousef ARA . Interleukin-1 and phospholipase A2 in septic newborns. Thesis submitted for partial fulfillment of master degree in pediatrics, faculty of medicine, Ain-Shams University. Supervised by Ismail IS, Imam SS, Shaheen KY 2003.

[13] Gomella TL, Cunningham MD, Eyal FG and ZenkEK . Tricia Lacy Gomella clinical manual of neonatology (5 thed). McGraw-Hill Co. 2004; 434-440.

[14] Abdel-Hady HE and ZakiME: Evaluation of soluble E-selectin as a marker for neonatal sepsis. The Egyptian journal of neonatology,2003; 4 (2): 69-78.

[15] Badrawi NH, Bashir MM, Iskander IF and Saied DA: Neonatal infections in NICU: magnitude of the problem. Kasr El-Aini Medical Journal,2005 ;11(5):181-195.

[16] Boseila S, Seoud I, Samy G, et al .Serum Neopterin Level in Early Onset Neonatal Sepsis. Journal of American Science ,2011; 7(7): 343-352.

[17] Mah MP, Aeberhard EE, Gilliam MB and Sherman MP :Effects of pentoxifylline on in vivo leukocyte function and clearance of group B streptococci from preterm rabbit lung. Crit Care Me, May 2002 ; 21(5): 712-20.

[18] Fergany AL .Serum cortisol and thyroid hormone levels in neonates with sepsis. Thesis submitted for partial fulfillment of Master degree in Pediatrics, Faculty of Medicine, AinShams University. Supervised by El Barbari MN, Imam SS, Shaheen KY-2006.

[19] El-Raggal NM, El-Barbary MN, Youssef MF, El-Mansy HA. Neutrophil surface antigens CD11b and CD64 expression: a potential predictor of early-onset neonatal sepsis. Egypt J Pediatr Allergy Immunol, 2004; 2 (2): 90-100.

[20] Carrigan SD, Scott G and TabrizianM .Toward resolving the challenges of sepsis diagnosis.ClinChem, 2004 ; 50:13011314 .

[21] Ng PC .Diagnostic markers of infection in neonates. Arch Dis Child Fetal Neonatal Ed, 2004 ; 89(3):F229-35.

[22] MitakaC . Clinical laboratory differentiation of infectious versus non- infectious systemic inflammatory response syndrome ClinChimActa, $2005 ; 351: 17$.

[23] Tasdelen Fisgin N, Aliyazicioglu Y, Tanyel E, et al .The value of neopterin and procalcitonin in patients with sepsis. South Med J,2010 ; 103(3):216-9.

[24] Baydar T, Yuksel O, Sahin TT, et al .Neopterin as a prognostic biomarker in intensive care unit patients. J Crit Care, 2009; 24(3): 318-21.

[25] Ruokonen E, Ilkka L, Niskanen M and TakalaJ.Procalcitonin and neopterin as indicators of infection in critically ill patients. ActaAnaesthesiol Scand,2002; 46(4):398-404.

[26] Murr C, Widner B, Wirleitner B and Fuchs D Neopterin as a Marker for Immune System Activation.J. Current Drug Metabolism ,2002;3:175-187. 